\title{
Efficacy and Safety of Anti-TNF $\alpha$ Therapy for Uveitis Associated with Juvenile Idiopathic Arthritis: A Systematic Review and Meta-Analysis
}

\author{
Yulu Li $\cdot$ Xiaolan Mao $\cdot$ Xuemei Tang $\cdot$ Huawei Mao
}

Received: January 1, 2021 / Accepted: February 13, 2021 / Published online: March 15, 2021

(C) The Author(s) 2021

\section{ABSTRACT}

Introduction: To investigate the efficacy and safety of anti-TNF $\alpha$ therapy in patients with juvenile idiopathic arthritis associated uveitis (JIA-U).

Methods: Embase, PubMed, Cochrane Library, and Web of Science were systematically searched for studies reporting anti-TNF $\alpha$ treatment in patients with JIA-U. The primary outcome was the control of intraocular inflammation (CII). The pooled proportion of CII was assessed by the random-effects method when $I^{2}>50 \%$, otherwise, by the fixed-effect method. This study was registered with PROSPERO (CRD42020161749).

Supplementary Information The online version contains supplementary material available at https:// doi.org/10.1007/s40744-021-00296-x.

Y. Li $\cdot$ X. Mao $\cdot$ X. Tang $\cdot$ H. Mao $(\bowtie)$ Department of Rheumatology and Immunology, National Clinical Research Center for Child Health and Disorders, Chongqing Key Laboratory of Child Infection and Immunity, Ministry of Education Key Laboratory of Child Development and Disorders, Children's Hospital of Chongqing Medical

University, Chongqing, China

e-mail: maohwei@qq.com

H. Mao

Department of Immunology, National Center for Children's Health, Beijing Children's Hospital of Capital Medical University, Beijing, China
Results: Three randomized clinical trials (RCTs), twelve case series, three retrospective cohort studies, and three case reports were identified. A total of 399 patients were receiving anti-TNF $\alpha$ therapy, of which 201 patients were treated with adalimumab (ADA), 139 with infliximab (IFX), 36 with etanercept (ETA), 20 with golimumab (GLM), and 3 with certolizumab pegol (CZP). The pooled proportions of CII on observational studies were $82 \%(95 \%$ CI 63-96\%) in patients receiving ADA, 56\% (95\% CI 30-80\%) in IFX, 38\% (95\% CI 8-73\%) in ETA and 65\% (95\% CI 42-86\%) in GLM, respectively. All three patients treated with CZP reached improved activity. ADA therapy led to a significantly higher proportion of CII compared to IFX therapy $\left(\chi^{2}=26.24, P<0.001\right)$, or to ETA therapy $\left(\chi^{2}=13.43, P<0.001\right)$; but no statistical difference was observed between IFX and ETA $\left(\chi^{2}=0.13, P=0.71\right)$. As to safety, most reported adverse events were tolerable and two cohort studies consistently showed that ADA was safer than IFX.

Conclusions: The existing evidence suggests that ADA is better than IFX regarding efficacy and safety. The effectiveness of IFX is higher than ETA with no statistical difference. GLM and CZP may be proxies for ADA but the evidence is limited.

Keywords: Anti-TNFa therapy; Efficacy; Juvenile idiopathic arthritis; Meta-analysis 


\section{Key Summary Points}

\section{Why carry out this study?}

Juvenile idiopathic arthritis(JIA) is the commonest rheumatic disease in children and uveitis is the commonest extraarticular manifestation of it. JIA associated uveitis(JIA-U) is still a big challenge for pediatric rheumatologists and ophthalmologists due to its insidious onset, sight-threatening complications and high refractory risk. In those who are refractory to topical glucocorticoids and methotrexate, anti-tumor necrosis factor $\alpha$ (anti-TNF $\alpha$ ) therapy is recommended by guidelines nowadays. However, high quality evidence of which anti-TNF $\alpha$ drug to choose and whether the choice is safe is still lacking.

Thus, a systematic review and metaanalysis was conducted to evaluate the efficacy and safety of anti-TNF $\alpha$ therapy in the treatment of JIA-U.

\section{What was learned from the study?}

The existing evidence suggests that adalimumab is the best anti-TNF $\alpha$ therapy for JIA-U treatment. Adalimumab is significantly better than infliximab and etanercept in the control of intraocular inflammation. Adalimumab is also better than infliximab in improving visual acuity and remaining in remission.

The efficacy of infliximab is higher than etanercept but with no statistical difference. Golimumab and certolizumab pegol may be proxies for adalimumab, but further evidence is needed.

Most reported adverse events of anti-TNF $\alpha$ therapy were tolerable. Some severe adverse events were reported but malignancy wasn't seen during the JIA-U treatment.

\section{DIGITAL FEATURES}

This article is published with digital features, including a summary slide to facilitate understanding of the article. To view digital features for this article go to https://doi.org/10.6084/ m9.figshare.13953848.

\section{INTRODUCTION}

Juvenile idiopathic arthritis (JIA) is one of the commonest rheumatic diseases in children. Uveitis is the commonest extra-articular manifestation of JIA and can develop even before the onset of arthritis [1]. Among all etiologies of uveitis in children, JIA accounts for a proportion ranging from 15 to $67 \%$ in Europe, North America, and Israel [2]. Uveitis can occur in different subtypes of JIA. Female gender, younger age of disease onset, oligoarthritis and antinuclear antibody (ANA) positivity are the main risk factors for the development of uveitis $[1,3,4]$. Anterior uveitis is the commonest (83\%) anatomical type associated with JIA, which includes acute anterior uveitis (AAU) and chronic anterior uveitis (CAU). AAU is typically associated with HLA-B27 and occurs in children with enthesitis-related or psoriatic arthritis. It often presents with overt symptoms, while generally doesn't need systemic treatment [5]. CAU is the commonest type of JIA-U and frequently associated with oligoarticular and rheumatoid factor negative polyarticular subtypes of JIA. The onset of CAU is usually insidious and mostly asymptomatic. Uncontrolled CAU can result in sight-threatening complications such as cataracts, glaucoma and even vision loss. In light of this, screening JIA patients regularly for uveitis is currently emphasized [6-8].

At present, a stepwise therapy strategy is adopted for children with JIA associated CAU. The initial treatment is topical glucocorticoids. In those who are refractory to or dependent on topical glucocorticoids, methotrexate is always used, followed by anti-tumor necrosis factor $\alpha$ (anti-TNF $\alpha$ ) biologic therapy [9, 10]. For severe active CAU and sight-threatening complications, the combination of methotrexate and 
anti-TNF $\alpha$ is conditionally recommended over methotrexate monotherapy by the American College of Rheumatology/Arthritis Foundation [7]. ETA is the first approved anti-TNF $\alpha$ biologic by the U.S. Food and Drug Administration for the treatment of JIA. As a greater incidence of new-onset uveitis is associated with ETA treatment than is seen with either ADA or IFX therapy [11], ETA is now generally not recommended for the treatment of pediatric uveitis. Instead, either ADA or IFX is recommended as the preferred agent, but evidence is not conclusive [7, 10, 12-14]. And it's still unclear which drug is the best and whether the choice is safety.

Thus, we herein performed a systematic review and meta-analysis to evaluate the efficacy and safety of anti-TNF $\alpha$ therapy in the treatment of JIA-U.

\section{METHODS}

\section{Information Sources and Search Strategy}

This study was performed following a predefined protocol registered with PROSPERO (CRD42020161749) and fully complied with PRISMA guidelines [15]. This article is based on previously conducted studies and does not contain any new studies with human participants or animals performed by any of the authors. A systematic search of Embase, PubMed, the Cochrane Library, and Web of Science was performed for relevant articles published from the commencement to 1 November 2019. The keywords comprised "JIA" or "JRA" or "juvenile rheumatoid arthritis" or "arthritis and (child* or kid)" crossed with "uveitis" or "JIAU" or "juvenile idiopathic arthritis associated uveitis", which were then crossed with "anti-tumor necrosis factor-alpha" or "anti-TNF $\alpha$ " or "etanercept" or "Enbrel" or "adalimumab" or "Humira" or "infliximab" or "Remicade" or "golimumab" or "Symponi" or "certolizumab pegol" or "Cimzia". The search strategies are shown in Supplementary Data S1.

\section{Eligibility Criteria}

To be eligible, studies were required: (1) to be focused on JIA-U; (2) to report data on patients with JIA onset at or before age 16; (3) to be starting one of the available anti-TNFa treatments for JIA-U with an inadequate response to topical steroids and DMARDs; (4) to include outcome measures assessing the efficacy or safety of anti-TNF $\alpha$ treatment; (5) to have at least a three-month follow-up; (6) to be published in English.

\section{Outcome Measures}

The primary outcome measure was the CII which mainly includes "improved activity" and "remission" according to Standardization of Uveitis Nomenclature (SUN) Working Group criteria [16]. Improved activity is a two-step decrease in the level of inflammation or decreases to grade 0 . Remission means inactive disease for 3 months after discontinuing all treatments for eye disease. Besides, some studies adopted other definitions, such as a 30\% reduction of inflammation on laser flare photometry, no relapse, etc. For a comprehensive analysis, we included all of these studies. As for secondary outcome measures, we considered the control of visual acuity (VA), and corticosteroid-sparing. Improved visual acuity was defined as a doubling of the visual angle in at least 1 eye which equals three lines on a decimal scale [17]. As for the definition of corticosteroidsparing, it was defined as a decrease by more than $50 \%$, or reductions to below $\leq 0.1 \mathrm{mg} / \mathrm{kg}$, or cessation of daily corticosteroid use [18]. Safety was assessed by the occurrence of adverse effects (AEs) and serious adverse effects (SAEs).

\section{Study Selection and Data Collection}

Firstly, two reviewers independently eliminated duplicates and irrelevant studies by reading the titles and abstracts. When abstract information was not enough to make a decision, we retrieved the full text further. For a comprehensive analysis, we not only included RCTs, cohort studies but also included qualified case 
series and case reports. Review papers, metaanalysis, editorial letters, and expert opinions were excluded to avoid duplication. Discrepancies in the process of study screening were resolved by discussion or consulting a third person. Data were extracted by one reviewer according to a standard form, and checked by a second reviewer.

\section{Risk of Bias in Individual Studies}

The Cochrane Collaboration risk of bias tool [19] was used to evaluate RCT from seven aspects: random sequence generation; allocation concealment; blinding of participants and personnel; blinding of outcome; incomplete outcome data; selective reporting and other unclear bias. The Revman software (Version 5.3) was used to visualize the results. The Newcastle-Ottawa Scale was applied to assess the risk of bias in cohort studies [20, 21]. Studies scoring $\geq 5$ and $\leq 8$ were designated as low risk of bias, $\geq 3$ and $\leq 4$ as moderate and $\leq 2$ as high. JBI critical appraisal checklists were used to assess the quality of case reports and case series [22].

\section{Statistical Analysis}

For the first outcome measure, we calculated the pooled proportions and 95\% confidence intervals (CIs). Heterogeneity across studies was measured by Cochrane's $\chi^{2}$ test and $I^{2}$ statistics [23]. $I^{2}>50 \%, p<0.1$ was regarded as statistically significant, then the random-effects model was used to present the pooled results, otherwise, a fixed-effect model (Mantel-Haenszel method) was used [19]. The pooled results were visualized with forest plots. The funnel plots were used to detect publication bias and heterogeneity. A Chi-square test was performed to determine whether there are statistical differences between the efficacy of ADA, IFX, and ETA. All the statistical analyses were conducted by R software (version 4.0.2).

\section{RESULTS}

\section{Study Selection and Characteristics}

A total of 1175 articles were retrieved by a computerized search. After 289 duplicates were automatically identified by Endnote, we excluded a further 813 studies by screening titles and abstracts. After assessing the full text of the remained 73 studies, we excluded another 52 studies. Overall, 21 articles were eligible: 10 on ADA, 7 on IFX, 3 on ETA, 2 on GLM, and 1 on CZP therapy. The reasons why other articles were excluded were shown in Fig. 1.

The majority of the included studies were retrospective case series with 12 articles. The rests were 3 RCTs, 3 retrospective cohort studies and 3 case reports. Table 1 showed the main characteristics of the 21 eligible articles. A total of 531 patients were included and 399 patients received anti-TNFa therapy. Of them, 201 received ADA, 139 received IFX, 36 received ETA, 20 received GLM, and 3 received CZP. Two articles did not reveal the patient gender $[24,25]$, and there were $293(61.6 \%)$ females in the remaining studies. Most studies included more women than men, except for one article[26]. The patients were followed up from 6 to 42.4 months with an average length of followup being 20.1 months.

\section{Risk of Bias within Studies}

Regarding three RCTs, a study conducted by Ramanan et al. [27] had a low risk of bias in all items. The other two studies [28, 29] had an unclear risk of bias in allocation concealment and blinding of outcome assessment. The study conducted by Janine A. Smith et al. [29] had another unclear risk of bias in randomization. All the three cohort studies were regarded as low risk of bias, of which two had a score of 8 out of 9 and the other one had a score of 7. As for case reports and case series, all the studies were considered qualified assessed by JBI critical appraisal. A summary of the quality assessments was presented in the Supplementary Table S1. 


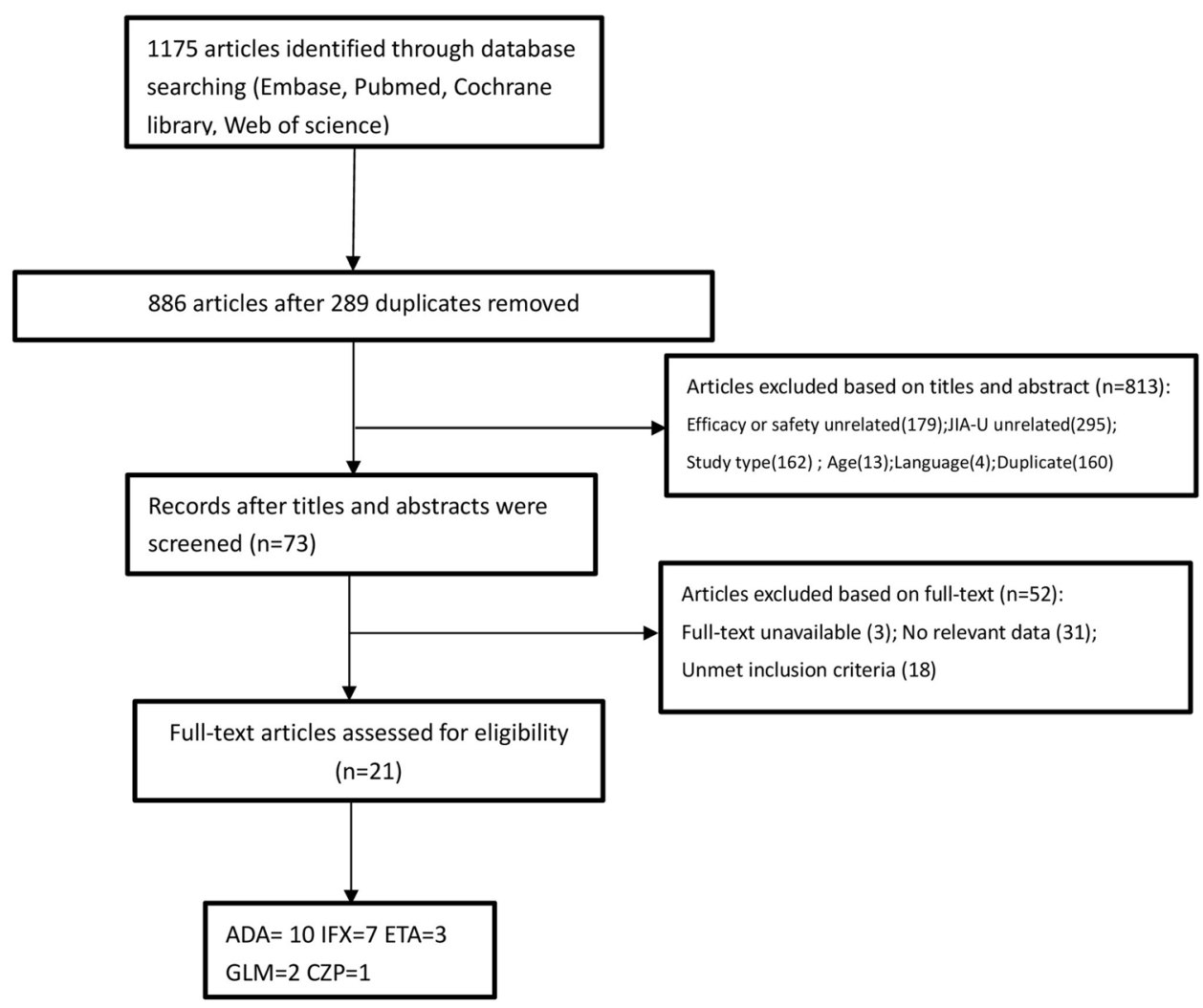

Fig. 1 The flow diagram of literature identification. $A D A$ adalimumab, $I F X$ infliximab, ETA etanercept, GLM golimumab, $C Z P$ certolizumab pegol

\section{Control of Intraocular Inflammation}

After the analysis, the pooled proportion of CII was $82 \% \quad(95 \%$ CI $63-96 \%), \quad 56 \% \quad(95 \%$ CI $30-80 \%)$ and $38 \%(95 \%$ CI $8-73 \%)$ for the treatment of ADA, IFX and ETA, respectively. The results were shown by forest plots in Fig. 2 . Because of the obvious heterogeneity, we chose the random-effects model to present the pooled results. The funnel plots showed the possible publication bias and heterogeneity in ADA, IFX and ETA (Fig. 3). We performed the Chi-square test to investigate the differences between ADA, IFX, and ETA. As demonstrated in Table 2, the CII proportion of ADA was much higher than that of IFX $\left(\chi^{2}=26.24, P<0.001\right)$ and ETA $\left(\chi^{2}=13.43, P<0.001\right)$, whereas no significant difference was indicated between IFX and ETA $\left(\chi^{2}=0.13, P=0.71\right)$. For GLM, the pooled proportion was $65 \%$ (95\% CI $42-86 \%)$. Only one qualified article containing three patients was retrieved for CZP treatment, and all three patients reached the criteria of SUN improved activity.

As for visual acuity, seven articles [30-36] were available for the analysis. Improved or stable VA was reported in 12 (92.3\%) out of 13 patients with ADA treatment, $9(90.0 \%)$ of 10 with IFX, 9 of 12 (75.0\%) with ETA, 13 (100.0\%) of 13 with GLM. In addition, two studies $[29,32]$ provided information regarding logMAR (logarithm of the minimum angle of resolution) and BCVA (best-corrected visual acuity). Quartier et al. [29] reported that the logMAR changed from 0.1 to 0.15 after ADA therapy. Palmou-Fontana et al. [32] reported that the BACV changed from 0.5 to 0.62 after IFX treatment.

Information on corticosteroid-sparing was extractable in nine of the eligible articles. The steroid-sparing, even discontinuation, was achieved in $26(72.2 \%)$ of 36 patients with ADA treatment, in $10(100 \%)$ of 10 patients with IFX 


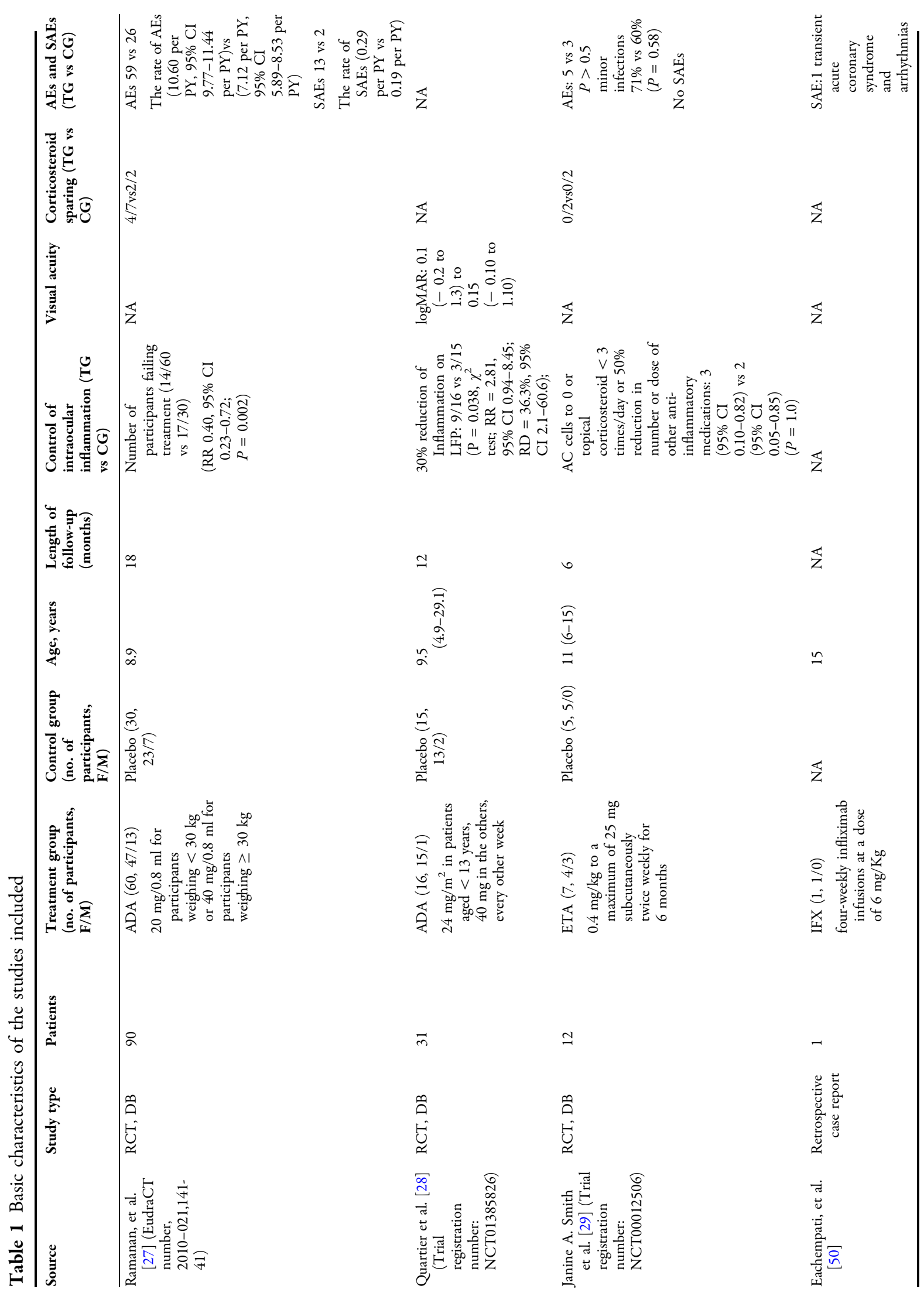




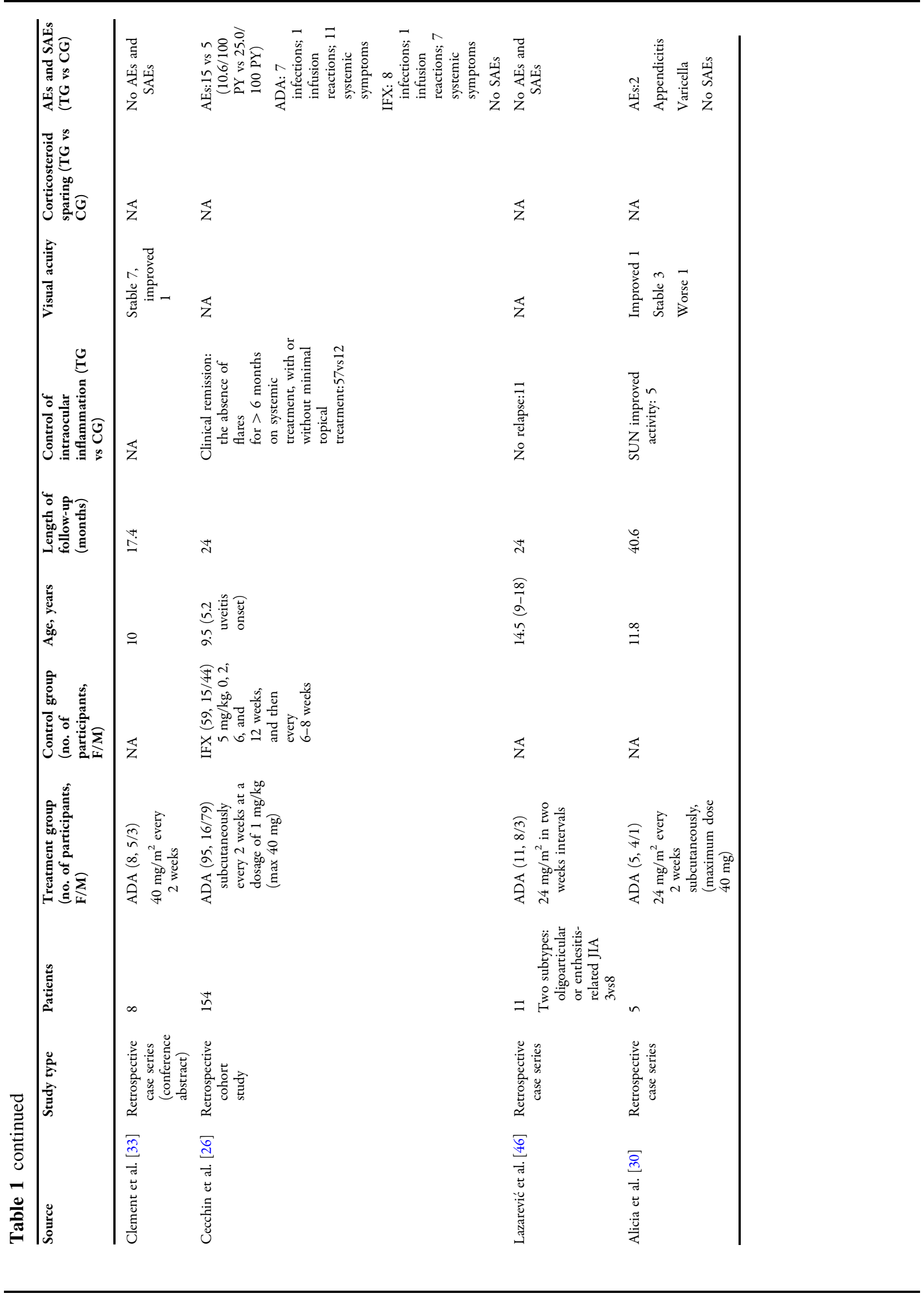




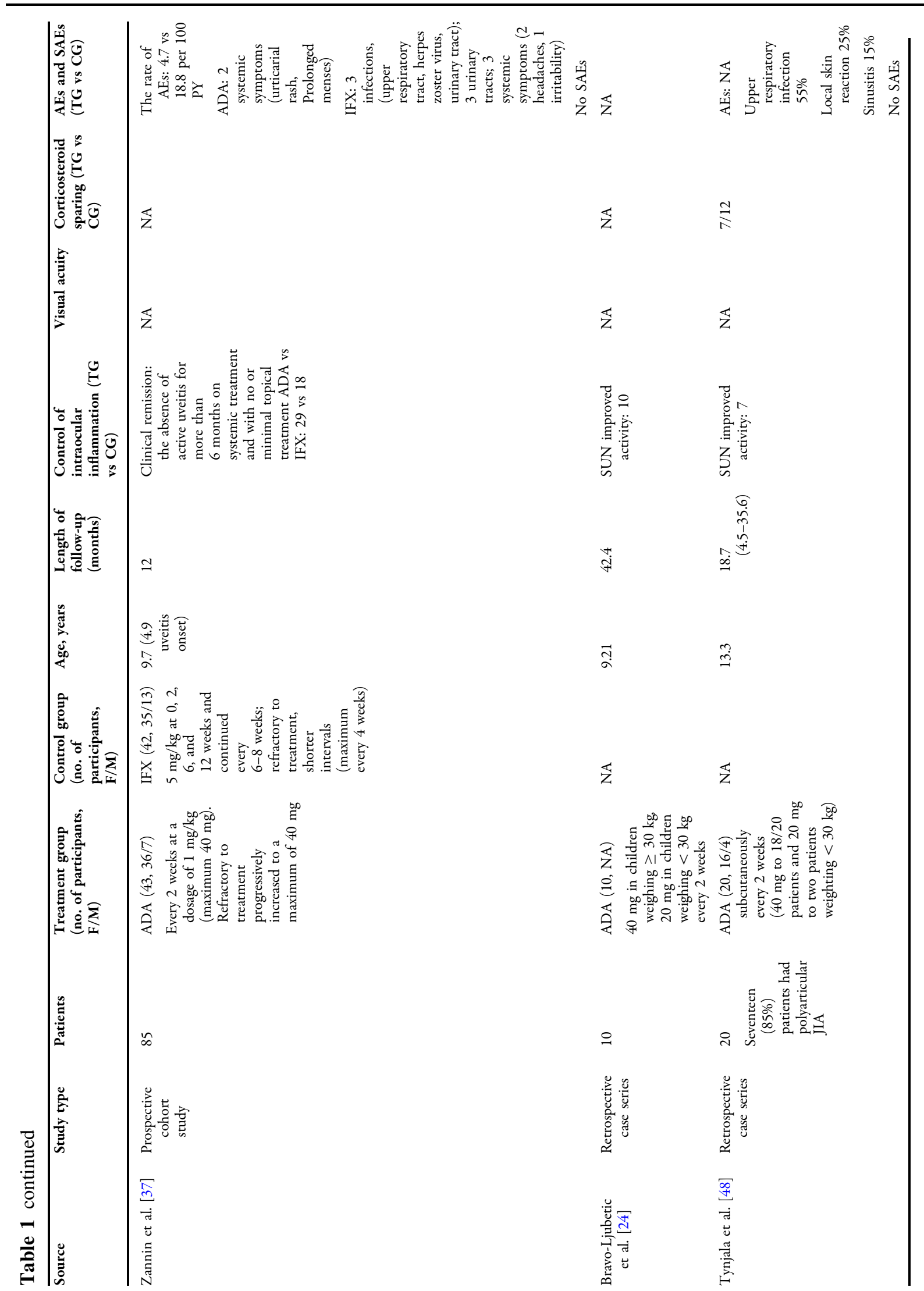




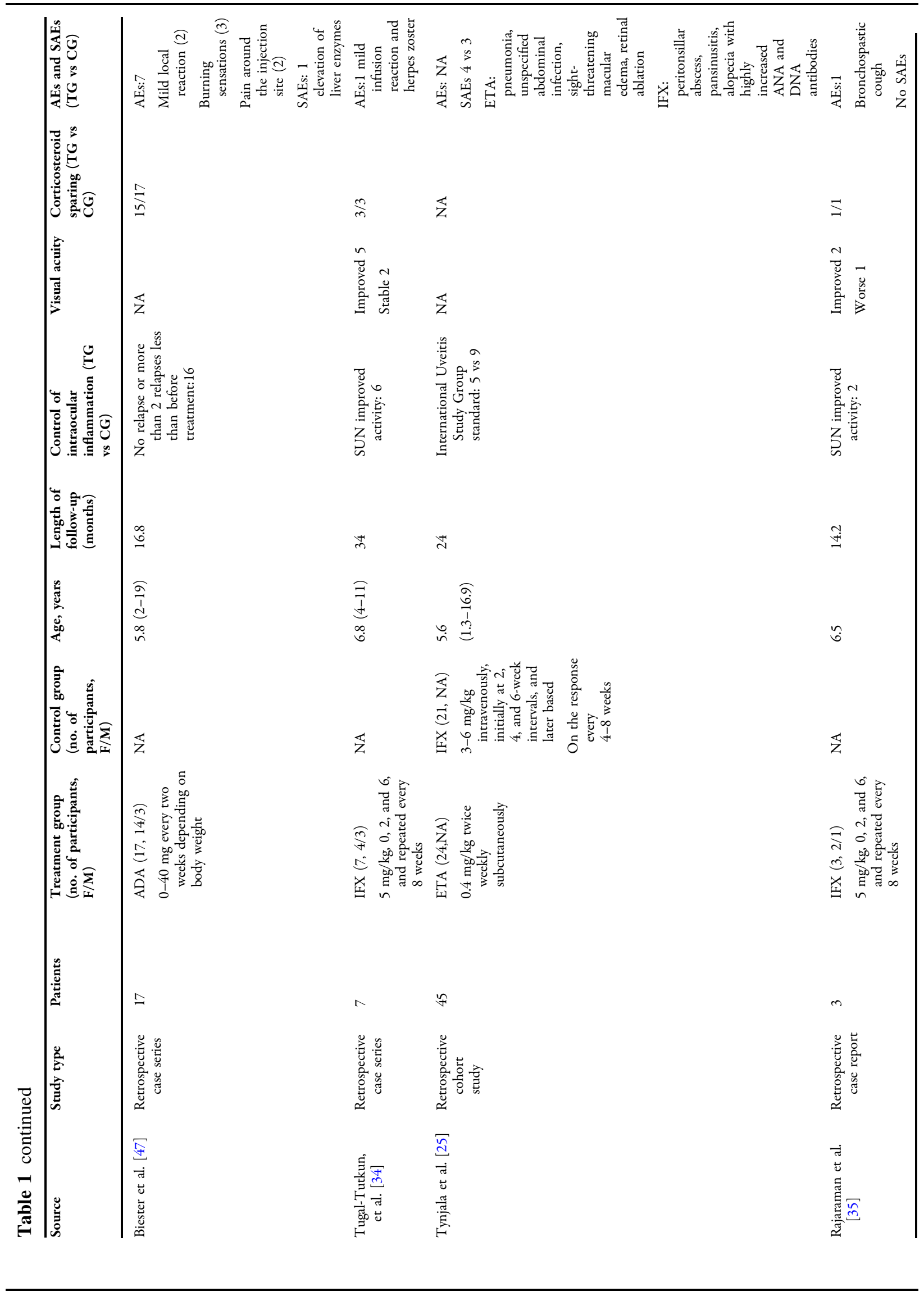




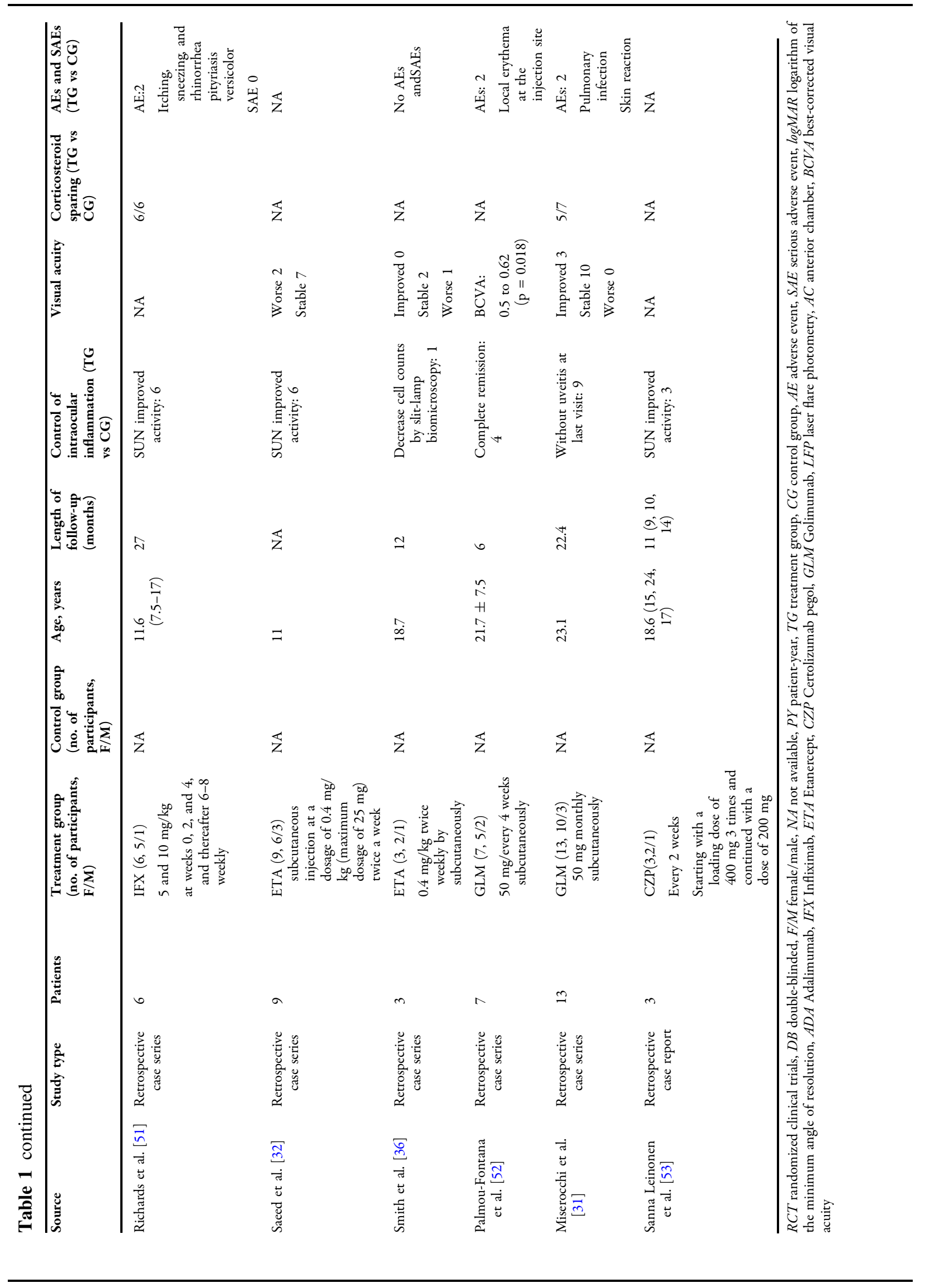


A: The pooled proportion of intraocular inflammation controlled of ADA

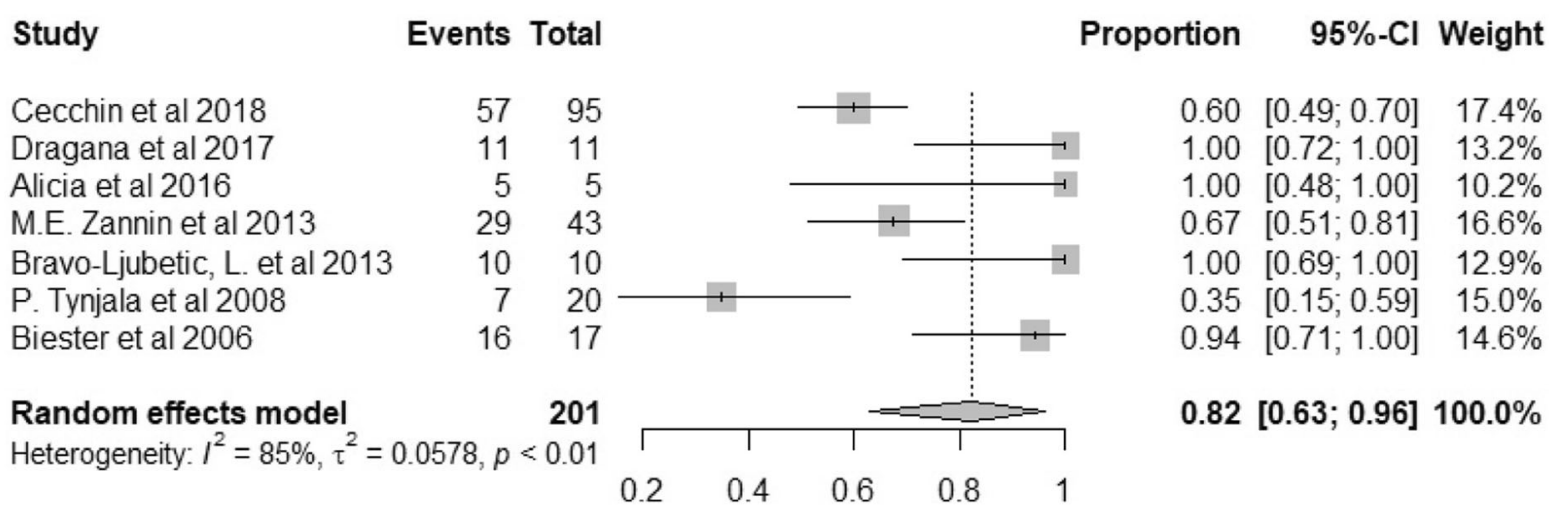

B: The pooled proportion of intraocular inflammation controlled of IFX

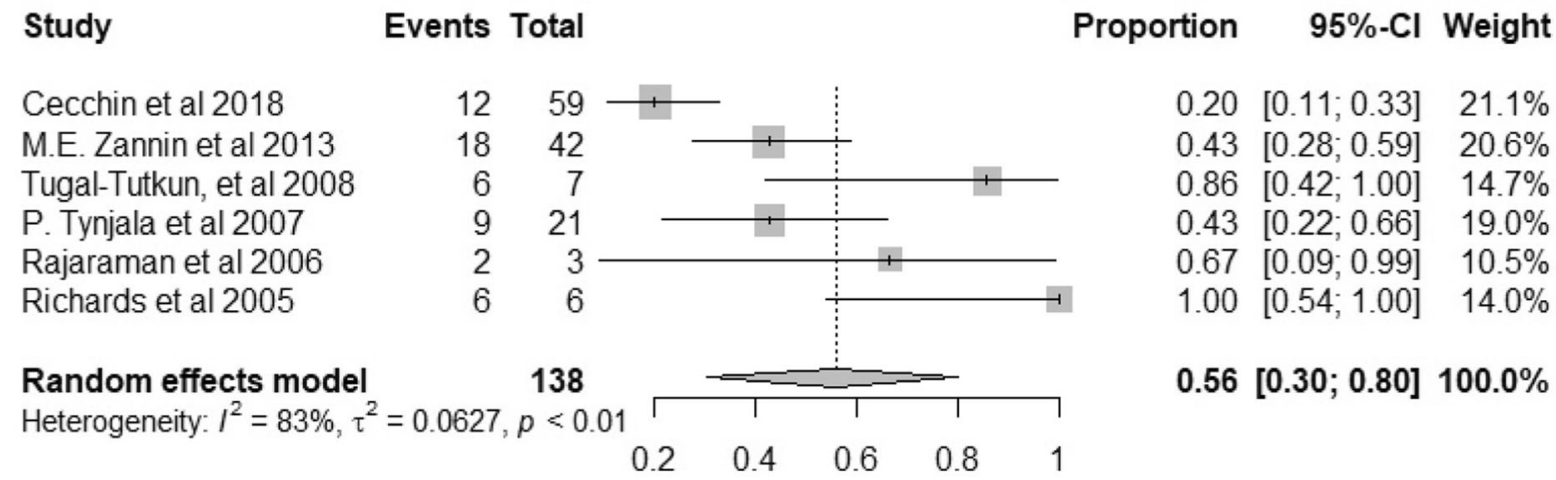

C: The pooled proportion of intraocular inflammation controlled of ETA

Study
$\begin{aligned} & \text { P. Tynjala et al 2007 } \\ & \text { Smith et al 2001 }\end{aligned}$
$\begin{aligned} & \text { Saeed et al 2013 } \\ & \text { Random effects model } \\ & \text { Heterogeneity: } I^{2}=64 \%, \tau^{2}=0.0478, p=0.06\end{aligned}$



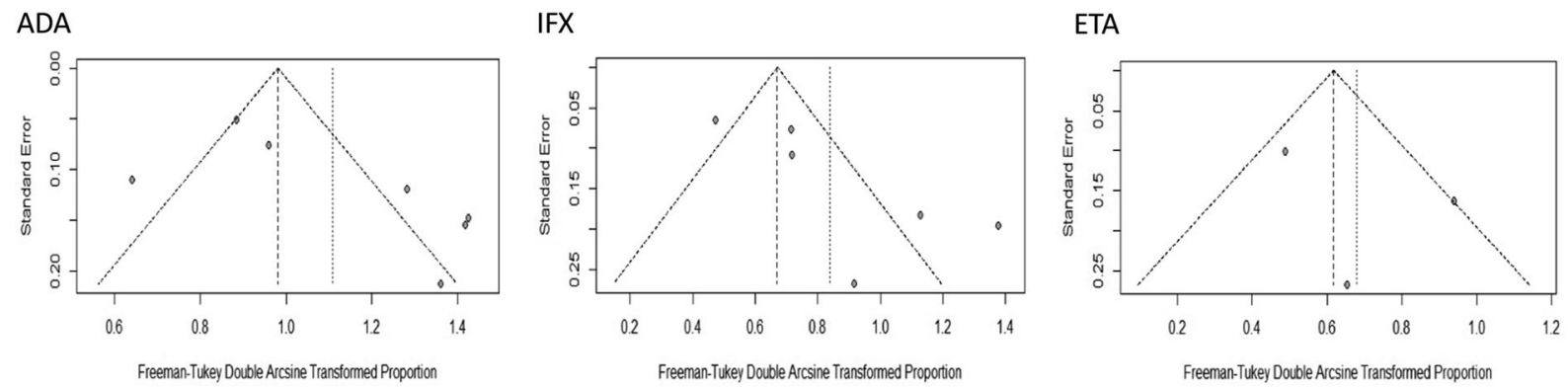

Fig. 3 Funnel plots on intraocular inflammation control in children with JIA-U regarding to adalimumab (ADA), infliximab (IFX), etanercept (ETA)

treatment, in $0(0 \%)$ of 2 patients with ETA treatment, and in $5(71.4 \%)$ of 7 patients with GLM treatment, respectively.

\section{Safety}

RCT conducted by Ramanan, et al. [27] indicated that the AE rate of ADA treatment (10.60 per Patient Year (PY), 95\% CI 9.77 to 11.44 per PY) was statistically different from that of the control group (7.12 per PY, 95\% CI 5.89 to 8.53 per PY) and the most common AEs of ADA were infections and infestations (83\%); while the rate of SAEs was low (0.29 per PY). The five SAEs in ADA were cataracts, injection site reactions, glaucoma, arthralgia and arthritis. Two cohort studies [26, 37] comparing ADA and IFX consistently showed that the AE rate of IFX was higher than that of ADA. In the cohort study conducted by P. Tynjala et al. [25], the SAEs were reported in $4 / 24(16.6 \%)$ patients during etanercept treatment and in 3/21 (14.3\%) patients taking infliximab. The reported SAEs in ETA were sight-threatening macular edema, retinal ablation, unspecified abdominal infection and pneumonia. As for IFX, the reported SAEs included peritonsillar abscess, pansinusitis and alopecia with highly increased ANA and DNA antibodies. In addition, Eachempati, S.B. et al. [28] reported a rare SAE of IFX, transient acute coronary syndrome and arrhythmias, which reminded us to be wary of sudden chest pain during or after the infusion of IFX. Regarding GLM and CZP, there were no special AEs and SAEs reported according to the currently availab information. The specific AEs and SAEs are listed in Table 1.

\section{DISCUSSION}

To the best of our knowledge, this is the first meta-analysis exploring the efficacy and safety of anti-TNFa therapy in JIA-U treatment. According to the analysis, ADA is the best choice. IFX is better than ETA but without statistical difference. GLM and CZP are effective for JIA-U patients, but more evidence is needed.

JIA-U is still a big challenge for pediatric rheumatologists and ophthalmologists due to its insidious onset, sight-threatening complications and difficulties in treating concomitant articular and ocular symptoms [38]. Patients with oligoarticular JIA and especially positive ANA are more prone to develop refractory uveitis. For them, the arthritis is often treatable with intra-articular corticosteroids and DMARDs, while the refractory uveitis needs timely systemic therapy including biologicals. Other subtypes, such as psoriatic and enthesitisrelated JIA, are rarely associated with refractory uveitis, probably because they receive systemic treatment early in the disease course. The key to JIA-U treatment is early detection through regular screening and timely control of disease activity. In children with JIA-U who don't respond to topical glucocorticoids and methotrexate, anti-TNFa therapy is usually added. Either ADA or IFX is recommended over ETA, as ETA is reported to be ineffective and at 
Table 2 Differences in the pooled proportion of intraocular inflammation control between adalimumab, infliximab, etanercept

\begin{tabular}{llllc}
\hline Adalimumab & Infliximab & Etanercept & Chi-square & $\boldsymbol{P}$ \\
\hline $82 \%$ & $56 \%$ & & 26.24 & $<0.001$ \\
$82 \%$ & & $38 \%$ & 13.43 & $<0.001$ \\
& $56 \%$ & $38 \%$ & 0.13 & 0.71 \\
\hline
\end{tabular}

high risk of new-onset uveitis or flares $[25,29,39,40]$.

In order to systematically evaluate the efficacy and safety of anti-TNF $\alpha$ therapy in patients with JIA-U, we performed a meta-analysis in this study. After a stepwise process of literature selection, three RCTs, twelve case series, three retrospective cohort studies, and three case reports were included. Based on the Cochrane handbook, results from different study designs are expected to differ systematically, leading to increased heterogeneity, therefore, randomized trials and non-randomized studies should not be combined in a meta-analysis. Accordingly, the three RCTs were not included for metaanalysis in this study, and instead carefully reviewed one by one. Their results are also in line with those of the meta-analysis. Significant efficacy was revealed for ADA treatment in two RCTs [27, 28], but not for ETA in another RCT[29]. There is no RCT exploring the efficacy of IFX in the treatment of JIA-U so far. In the meta-analysis, the pooled proportion of CII was $82 \%, 56 \%$ and $38 \%$ for ADA, IFX and ETA respectively. ADA is significantly better than IFX and ETA in the control of intra-ocular inflammation, but no statistical difference was found between IFX and ETA. ADA is also better than IFX in improving or stabling VA. In addition, a cohort study [41] showed that uveitis was more likely to remain in remission in those receiving ADA than IFX during 40 months of follow-up. Unlike our results, a meta-analysis conducted in 2014 did not show any significant difference between ADA and IFX in the treatment of childhood autoimmune chronic uveitis [42]. The difference of the two meta-analyses may come from two aspects. One is that our study focused on JIA-U patients but they explored all the childhood autoimmune uveitis.
In addition, after their analysis in 2014, more studies have been performed and more evidence accumulated in recent years. Our results would be closer to the real situation. As for GLM and CZP, although good efficacy have been seen in controlling intraocular inflammation, their efficacy still needs further verification because of the limited number of studies.

As for safety, most reported adverse events of anti-TNF $\alpha$ therapy were tolerable, and some SAEs were reported. The development of malignancy wasn't revealed during the JIA-U treatment, which may be due to a paucity of long-term follow-up studies. The risk of the development of malignancies after anti-TNFa therapy is still inconclusive. Meta-analysis in other diseases showed that the risk of malignancy did not increase in the short-term treatment $[43,44]$. However, in the registry of some health authorities, the incidence of lymphoma and melanoma has increased [45]. Clinicians should still bear in mind the risk of the development of malignancies, especially in patients with previous malignancy or premalignant status.

Several limitations have to be considered for this meta-analysis. First, the majority of the studies included are case series. Its inherent low evidence strength makes our conclusion less persuasive. There is an urgent need for high quality studies. Second, the definition of outcome measures was inconsistent. Clinical remission [26, 37], no relapse [46, 47] or SUN improved uveitis $[24,30,48]$ were used as outcome measures in different studies, which may lead to obvious heterogeneity. Although the SUN criteria have made a huge contribution to standardizing outcome reporting, many clinical trials still have not reached consensus nowadays $[42,49]$. The broad variety of outcome measures 
makes the comparison of responses to different treatments quite difficult. Third, the different features of participants in different studies may also lead to the obvious heterogeneity. In order to improve the quality of meta-analysis in the future, more studies with high quality, uniform outcome measures and clear identification of patients are warranted.

\section{CONCLUSION}

In conclusion, $\mathrm{ADA}$ is better than IFX for JIA-U treatment with respect to its efficacy and safety. The efficacy of IFX is higher than ETA but with no statistical significance. In addition, GLM and CZP may be proxies for ADA but more evidence is needed.

\section{ACKNOWLEDGEMENTS}

Funding. Sponsorship for this study and Rapid Service Fee were funded by the National Natural Science Foundation of China (81971547) and the Research Fund for Outstanding Youth Scholar of Chongqing Talents (CQYC201905003).

Authorship. All named authors meet the International Committee of Medical Journal Editors (ICMJE) criteria for authorship for this article, take responsibility for the integrity of the work as a whole, and have given their approval for this version to be published.

Authorship Contributions. Huawei Mao conceived, designed, guided the study, and revised the manuscript critically. Yulu Li involved in all parts of the study: design, acquisition of data, analysis, interpretation, and drafting of manuscript. Xiaolan Mao took part in the screening of the qualified articles and the checking of the included information. Xuemei Tang, involved in the data interpretation and the revision of the manuscript.

Disclosures. Yulu Li, Xiaolan Mao, Xuemei Tang and Huawei Mao have nothing to disclose.
Compliance with Ethics Guidelines. This article is based on previously conducted studies and does not contain any new studies with human participants or animals performed by any of the authors.

Data Availability. All data generated or analyzed during this study are included in this published article or as supplementary files.

Open Access. This article is licensed under a Creative Commons Attribution-NonCommercial 4.0 International License, which permits any non-commercial use, sharing, adaptation, distribution and reproduction in any medium or format, as long as you give appropriate credit to the original author(s) and the source, provide a link to the Creative Commons licence, and indicate if changes were made. The images or other third party material in this article are included in the article's Creative Commons licence, unless indicated otherwise in a credit line to the material. If material is not included in the article's Creative Commons licence and your intended use is not permitted by statutory regulation or exceeds the permitted use, you will need to obtain permission directly from the copyright holder. To view a copy of this licence, visit http://creativecommons.org/licenses/by$\mathrm{nc} / 4.0 /$.

\section{REFERENCES}

1. Heiligenhaus A, Heinz C, Edelsten C, Kotaniemi K, Minden K. Review for disease of the year: epidemiology of juvenile idiopathic arthritis and its associated uveitis: the probable risk factors. Ocul Immunol Inflamm. 2013;21(3):180-91.

2. Clarke SLN, Sen ES, Ramanan AV. Juvenile idiopathic arthritis-associated uveitis. Pediatr Rheumatol Online J. 2016;14(1):27.

3. Heiligenhaus A, Niewerth M, Ganser G, Heinz C, Minden K. Prevalence and complications of uveitis in juvenile idiopathic arthritis in a populationbased nation-wide study in Germany: suggested modification of the current screening guidelines. Rheumatology (Oxford). 2007;46(6):1015-9.

4. Nordal E, Rypdal V, Christoffersen T, Aalto K, Berntson L, Fasth A, et al. Incidence and predictors 
of Uveitis in juvenile idiopathic arthritis in a Nordic long-term cohort study. Pediatr Rheumatol Online J. 2017;15(1):66.

5. Tay-Kearney ML, Schwam BL, Lowder C, Dunn JP, Meisler DM, Vitale S, et al. Clinical features and associated systemic diseases of HLA-B27 uveitis. Am J Ophthalmol. 1996;121(1):47-56.

6. Holland GN, Denove CS, Yu F. Chronic anterior uveitis in children: clinical characteristics and complications. Am J Ophthalmol. 2009;147(4): 67800000.

7. Angeles-Han ST, Ringold S, Beukelman T, Lovell D, Cuello CA, Becker ML, et al. 2019 American College of Rheumatology/Arthritis Foundation Guideline for the Screening, Monitoring, and Treatment of Juvenile Idiopathic Arthritis-Associated Uveitis. Arthritis Care Res. 2019;71(6):703-16.

8. Gregory AC, Kempen JH, Daniel E, Kaçmaz RO, Foster CS, Jabs DA, et al. Risk factors for loss of visual acuity among patients with uveitis associated with juvenile idiopathic arthritis: the Systemic Immunosuppressive Therapy for Eye Diseases Study. Ophthalmology. 2013;120(1):186-92.

9. Henderson LA, Zurakowski D, Angeles-Han ST, Lasky A, Rabinovich CE, Lo MS. Medication use in juvenile uveitis patients enrolled in the Childhood Arthritis and Rheumatology Research Alliance Registry. Pediatr Rheumatol. 2016;14(1):1-10.

10. Bou R, Adán A, Borrás F, Bravo B, Calvo I, De Inocencio J, et al. Clinical management algorithm of uveitis associated with juvenile idiopathic arthritis: interdisciplinary panel consensus. Rheumatol Int. 2015;35(5):777-85.

11. Lim LL, Fraunfelder FW, Rosenbaum JT. Do tumor necrosis factor inhibitors cause uveitis? A registrybased study. Arthritis Rheum. 2007;56(10): 3248-52.

12. Angeles-Han ST, Lo MS, Henderson LA, Lerman MA, Abramson L, Cooper AM, et al. Childhood arthritis and rheumatology research alliance consensus treatment plans for juvenile idiopathic arthritis-associated and idiopathic chronic anterior uveitis. Arthritis Care Res. 2019;71(4):482-91.

13. Sen ES, Ramanan AV. Juvenile idiopathic arthritisassociated uveitis. Best Pract Res Clin Rheumatol. 2017;31(4):517-34.

14. Constantin T, Foeldvari I, Anton J, de Boer J, Czitrom-Guillaume S, Edelsten $\mathrm{C}$, et al. Consensusbased recommendations for the management of uveitis associated with juvenile idiopathic arthritis: the SHARE initiative. Ann Rheum Dis. 2018;77(8): 1107-17.
15. Moher D, Liberati A, Tetzlaff J, Altman DG. Preferred reporting items for systematic reviews and meta-analyses: the PRISMA statement. PLoS Med. 2009;6(7):e1000097.

16. Jabs DA, Nussenblatt RB, Rosenbaum JT, Standardization of Uveitis Nomenclature Working G. Standardization of uveitis nomenclature for reporting clinical data. Results of the First International Workshop. Am J Ophthalmol. 2005;140(3):509-16.

17. Jabs DA. Improving the reporting of clinical case series. Am J Ophthalmol. 2005;139(5):905.

18. Heiligenhaus A, Foeldvari I, Edelsten C, Smith JR, Saurenmann RK, Bodaghi B, et al. Proposed outcome measures for prospective clinical trials in juvenile idiopathic arthritis-associated uveitis: a consensus effort from the multinational interdisciplinary working group for uveitis in childhood. Arthritis Care Res. 2012;64(9):1365-72.

19. Higgins JPT, Altman DG, Gøtzsche PC, Jüni P, Moher D, Oxman AD, et al. The Cochrane Collaboration's tool for assessing risk of bias in randomised trials. BMJ (Clinical research ed). 2011;343:d5928.

20. Wells BSGA, O'Connell D, Peterson J, Welch V, Losos M, Tugwell P, et al. The Newcastle-Ottawa Scale (NOS) for assessing the quality of nonrandomised studies in meta-analyses. http://www.ohri. ca/programs/clinical_epidemiology/oxford.asp.

21. Stang A. Critical evaluation of the Newcastle-Ottawa scale for the assessment of the quality of nonrandomized studies in meta-analyses. Eur J Epidemiol. 2010;25(9):603-5.

22. Munn Z, Barker TH, Moola S, Tufanaru C, Stern C, McArthur A, et al. Methodological quality of case series studies: an introduction to the JBI critical appraisal tool. JBI Evid Synth. 2019.

23. Higgins JPT, Thompson SG, Deeks JJ, Altman DG. Measuring inconsistency in meta-analyses. BMJ. 2003;327(7414):557-60.

24. Bravo-Ljubetic L, Peralta-Calvo J, Noval S, PastoraSalvador N, Abelairas-Gomez J, Merino R. Adalimumab therapy for refractory childhood uveitis. J AAPOS. 2013;17(5):456-9.

25. Tynjälä $\mathrm{P}$, Lindahl $\mathrm{P}$, Honkanen $\mathrm{V}$, Lahdenne $\mathrm{P}$, Kotaniemi K. Infliximab and etanercept in the treatment of chronic uveitis associated with refractory juvenile idiopathic arthritis. Ann Rheum Dis. 2007;66(4):548-50.

26. Cecchin V, Zannin ME, Ferrari D, Pontikaki I, Miserocchi $\mathrm{E}$, Paroli $\mathrm{MP}$, et al. Longterm safety and efficacy of adalimumab and infliximab for uveitis 
associated with juvenile idiopathic arthritis. J Rheumatol. 2018;45(8):1167-72.

27. Ramanan AV, Dick AD, Jones AP, Hughes DA, McKay A, Rosala-Hallas A, et al. Adalimumab in combination with methotrexate for refractory uveitis associated with juvenile idiopathic arthritis: a Rct. Health Technol Assess. 2019;23(15):1-139.

28. Quartier P, Baptiste A, Despert V, Allain-Launay E, Koné-Paut I, Belot A, et al. ADJUVITE: a doubleblind, randomised, placebo-controlled trial of adalimumab in early onset, chronic, juvenile idiopathic arthritis-associated anterior uveitis. Ann Rheum Dis. 2018;77(7):1003-11.

29. Smith JA, Thompson DJS, Whitcup SM, Suhler E, Clarke G, Smith S, et al. A randomized, placebocontrolled, double-masked clinical trial of etanercept for the treatment of uveitis associated with juvenile idiopathic arthritis. Arthritis Care Res. 2005;53(1):18-23.

30. Alicia BE, Enríquez E, Tejada P, Barceló A, de Inocencio J. Adalimumab for the treatment of refractory noninfectious paediatric uveitis. Int Ophthalmol. 2017;37(3):719-25.

31. Miserocchi E, Modorati G, Pontikaki I, Meroni PL, Gerloni V. Long-term treatment with golimumab for severe uveitis. Ocul Immunol Inflamm. 2014;22(2):90-5.

32. Saeed MU, Raza SH, Goyal S, Cleary G, Newman WD, Chandna A. Etanercept in methotrexate-resistant JIA-related uveitis. Semin Ophthalmol. 2014;29(1):1-3.

33. Clement A, Valls I, Gutierrez B, Jimenez C. Adalimumab in the therapy of juvenile idiopathic arthritisassociated uveitis. J AAPOS. 2009;13(1):e13.

34. Tugal-Tutkun I, Ayranci O, Kasapcopur O, Kir N. Retrospective analysis of children with uveitis treated with infliximab. J AAPOS. 2008;12(6):611-3.

35. Rajaraman RT, Kimura Y, Li S, Haines K, Chu DS. Retrospective case review of pediatric patients with uveitis treated with infliximab. Ophthalmology. 2006;113(2):308-14.

36. Smith JR, Levinson RD, Holland GN, Jabs DA, Robinson MR, Whitcup SM, et al. Differential efficacy of tumor necrosis factor inhibition in the management of inflammatory eye disease and associated rheumatic disease. Arthritis Rheum. 2001;45(3):252-7.

37. Zannin ME, Birolo C, Gerloni VM, Miserocchi E, Pontikaki I, Paroli MP, et al. Safety and efficacy of infliximab and adalimumab for refractory uveitis in juvenile idiopathic arthritis: 1-year followup data from the Italian Registry. J Rheumatol. 2013;40(1): 74-9.

38. Skarin A, Elborgh R, Edlund E, Bengtsson-Stigmar E. Long-term follow-up of patients with uveitis associated with juvenile idiopathic arthritis: a cohort study. Ocul Immunol Inflamm. 2009;17(2):104-8.

39. Saurenmann RK, Levin AV, Feldman BM, Laxer RM, Schneider R, Silverman ED. Risk of new-onset uveitis in patients with juvenile idiopathic arthritis treated with anti-TNFalpha agents. J Pediatr. 2006;149(6):833-6.

40. Schmeling H, Horneff G. Etanercept and uveitis in patients with juvenile idiopathic arthritis. Rheumatology (Oxford). 2005;44(8):1008-11.

41. Simonini G, Taddio A, Cattalini M, Caputo R, De Libero C, Naviglio S, et al. Prevention of flare recurrences in childhood-refractory chronic uveitis: an open-label comparative study of adalimumab versus infliximab. Arthritis Care Res. 2011;63(4): 612-8.

42. Simonini G, Druce K, Cimaz R, Macfarlane GJ, Jones GT. Current evidence of anti-tumor necrosis factor $\alpha$ treatment efficacy in childhood chronic uveitis: a systematic review and meta-analysis approach of individual drugs. Arthritis Care Res. 2014;66(7):1073-84.

43. Bongartz T, Warren FC, Mines D, Matteson EL, Abrams KR, Sutton AJ. Etanercept therapy in rheumatoid arthritis and the risk of malignancies: a systematic review and individual patient data metaanalysis of randomised controlled trials. Ann Rheum Dis. 2009;68(7):1177-83.

44. Williams CJM, Peyrin-Biroulet L, Ford AC. Systematic review with meta-analysis: malignancies with anti-tumour necrosis factor- $\alpha$ therapy in inflammatory bowel disease. Aliment Pharmacol Ther. 2014;39(5):447-58.

45. Askling J, Dixon W. The safety of anti-tumour necrosis factor therapy in rheumatoid arthritis. Curr Opin Rheumatol. 2008;20(2):138-44.

46. Lazarević D, Nikolić I, Ratković-Janković M, Vojinović J. Outcome of juvenile idiopathic arthritis associated uveitis in two disease subtypes. Arch Rheumatol. 2017;32(1):26-31.

47. Biester S, Deuter C, Michels H, Haefner R, Kuemmerle-Deschner J, Doycheva D, et al. Adalimumab in the therapy of uveitis in childhood. Br J Ophthalmol. 2007;91(3):319-24.

48. Tynjala P, Kotaniemi K, Lindahl P, Latva K, Aalto K, Honkanen $\mathrm{V}$, et al. Adalimumab in juvenile 
idiopathic arthritis-associated chronic anterior uveitis. Rheumatology (Oxford). 2008;47(3): 339-44.

49. Mastrangelo G, Foeldvari I, Anton J, Simonini G. Defining outcome measures in juvenile idiopathic arthritis associated uveitis by a systematic review analysis: do we need a consensus? Pediatr Rheumatol Online J. 2019;17(1):40.

50. Eachempati SB, Shastri A, Armon K. Arrhythmias and acute coronary syndrome after infliximab therapy in a child with juvenile idiopathic arthritis. Rheumatology (United Kingdom). 2018;57:viii14.
51. Richards JC, Tay-Kearney ML, Murray K, Manners P. Infliximab for juvenile idiopathic arthritis-associated uveitis. Clin Experiment Ophthalmol. 2005;33(5):461-8.

52. Palmou-Fontana N, Calvo-Río V, Martín-Varillas JL, Fernández-Díaz C, Mesquida $\mathrm{M}$, Adán $\mathrm{A}$, et al. Golimumab in refractory uveitis associated to juvenile idiopathic arthritis: multicentre study of 7 cases and literature review. Clin Exp Rheumatol. 2018;36(4):652-7.

53. Leinonen S. Certolizumab pegol in treating JIA-related uveitis. Acta Ophthalmol. 2016;94:4. 